\title{
Using Twitter to assess attitudes to schizophrenia and psychosis
}

\author{
Giorgianna L. Passerello, ${ }^{1}$ James E. Hazelwood, ${ }^{1}$ Stephen Lawrie ${ }^{2}$ (1)
}

BJPsych Bulletin (2019) 43, 158-166, doi:10.1192/bjb.2018.115

'Edinburgh Medical School, College of Medicine and Veterinary Medicine, University of Edinburgh, UK; ${ }^{2}$ Royal Edinburgh Hospital, University of Edinburgh, UK

Correspondence to Stephen Lawrie (s.lawrie@ed.ac.uk)

First received 1 Aug 2018, final revision 20 Nov 2018, accepted 7 Dec 2018

(c) The Authors 2019. This is an Open Access article, distributed under the terms of the Creative Commons

Attribution-NonCommercial-

NoDerivatives licence (http:// creativecommons.org/licenses/by-ncnd/4.0/), which permits noncommercial re-use, distribution, and reproduction in any medium, provided the original work is unaltered and is properly cited. The written permission of Cambridge University Press must be obtained for commercial re-use or in order to create a derivative work.
Aims and method Schizophrenia is a psychotic disorder that is stereotypically stigmatised as untreatable and associated with violence. Several authorities have suggested that changing the name, for example to psychosis, would reduce such stigmatisation. We aimed to compare attitudes to schizophrenia and psychosis on Twitter to see if psychosis was associated with less negative attitudes. Tweets containing the terms 'schizophrenia', 'schizophrenic', 'psychosis' or 'psychotic' were collected on www.twitter.com and were captured with NCapture. On NVivo, tweets were coded into categories based on user type, tweet content, attitude and stigma type by two independent raters. We compared the content and attitudes of tweets referring to schizophrenia/schizophrenic and psychosis/psychotic.

Results A total of 1120 tweets referring to schizophrenia/schizophrenic and 1080 referring to psychosis/psychotic were identified over two 7-day periods; 424 original tweets for schizophrenia and 416 original tweets for psychosis were included in the analysis. Psychosis was significantly more commonly included in tweets expressing negative attitudes $(n=131,31.5 \%)$ than schizophrenia $(n=41,9.7 \%)\left(\chi^{2}=237.03, P<\right.$ $0.0001)$. Of the personal opinions or dyadic interactions, $125(53.4 \%)$ in the psychosis data set were stigmatising, compared with $33(24.6 \%)$ of those in the schizophrenia set $\left(\chi^{2}=44.65, P<0.0001\right)$.

Clinical implications The terms psychosis/psychotic are associated with a significantly higher number of tweets with negative content than schizophrenia/ schizophrenic. Together with other evidence, this suggests that changing the name of schizophrenia to psychosis will not reduce negative attitudes toward the condition.

Declaration of interest S.L. has received personal fees from Otsuka and Sunovion, and personal and research fees from Janssen.

Keywords Stigma and discrimination; schizophrenia; psychotic disorders.

\section{Schizophrenia and stigma}

Schizophrenia is the prototypical psychotic disorder and is characterised by the psychotic symptoms of hallucinations, delusions, disorganised speech, grossly disorganised or catatonic behaviour, and negative symptoms. ${ }^{1}$ Typically, people with schizophrenia suffer from social or occupational dysfunction, such that only a minority will be able to live independently and obtain paid employment. ${ }^{2}$ Nevertheless, around half of those with schizophrenia can be regarded as having a relatively good outcome $\mathrm{e}^{3}$ and most will derive some benefit from antipsychotic medication. ${ }^{4}$

People with schizophrenia face a great deal of stigma, which is defined as a 'negative attitude (based on prejudice and misinformation) that is triggered by a marker of illness' ${ }^{5}$ This affects their social life, occupation, self-esteem, confidence and ability to seek help and succeed with treatment ${ }^{5}$. Stigma may even be 'the main obstacle to the success of programmes to improve mental health'. ${ }^{5}$ For example, young people with schizophrenia are likely to delay seeking treatment because of perceived stigma and the concerns that it would harm their chances of getting jobs, they would not be taken seriously and would be seen as weak. ${ }^{6}$ Indeed, the way that members of healthcare teams treat patients with schizophrenia is affected by stigma; for example, in reducing the willingness and confidence of pharmacists to provide medication counselling to people with schizophrenia. ${ }^{7}$ Further, people with the diagnosis of schizophrenia often stigmatise themselves in that they regard themselves negatively, and such 'self-stigma' is associated with poor neurocognitive function. ${ }^{8}$

\section{Changing the name of schizophrenia}

There has been debate as to whether renaming schizophrenia would reduce the negative attitudes expressed about people with the condition. A narrative literature review concluded that the advantages of a name change would outweigh the disadvantages and suggested that an eponym be used, ${ }^{9}$ although 
this conclusion was based largely on expert opinion. A recent systematic review found that in countries that have adopted a name change, the results have been inconclusive. ${ }^{10}$ The names changed from and to are likely to be important. For example, in Japan, what was called mind-split disease (a literal translation of the Greek origins of the word schizophrenia) was renamed integration disorder. ${ }^{10}$ Koike et $a l^{11}$ found that this name change 'had a limited effect', whereas Aoki et $a l^{12}$ found some improvement in reducing the frequency of reporting an association with violence.

In the English-speaking world, many authorities are beginning to abandon the use of the term schizophrenia both in clinical practice and in the academic literature, and increasingly refer to the condition as psychosis (e.g. Sami et $a l^{13}$ ). For example, the former Schizophrenia Bulletin recently changed title to Schizophrenia Bulletin: The Journal of Psychoses and Related Disorders in a bid to acknowledge the changing ideas about the diagnosis of schizophrenia. ${ }^{14}$ In 2016, van Os suggested a name changed to psychosis susceptibility syndrome and that the ICD-11 should remove schizophrenia as a term. ${ }^{15}$ The authors of the British Psychological Society's report Understanding Psychosis and Schizophrenia debated whether even to use the word schizophrenia in the title of their report. ${ }^{16,17}$ They argued that symptoms of schizophrenia and psychosis are not necessarily mental illness, and labelling all patients who fulfil diagnostic criteria for schizophrenia as having a mental illness can be detrimental and cause more harm than good because of stereotypes and stigmatising views from patients themselves and society. They argue 'schizophrenia is essentially an idea' and does not explain the aetiology or likely outcome for a patient. ${ }^{16}$ The move to psychosis appears to be based on the assumption that this term will carry less of the negative connotations with severity, chronicity, untreatability and violence associated with schizophrenia. For example, it has been shown that the chances of recovery for a patient diagnosed with schizophrenia (13.5\%) may be less than for those who have experienced only first-episode psychosis $(38 \%) .^{18,19}$ To our knowledge, this assumption of a reduction in stigma has not been tested. Therefore, we wished to examine if and how the word psychosis and the related term psychotic are used. If it was found that people talk less negatively about psychosis than schizophrenia, it would provide some support for the view that making such a change in official documents, scientific papers and clinical services would reduce stigma.

\section{The role of social media}

One way of assessing how different conditions are referred to and discussed is to examine the usage of various terms on social media. Many people use social media as an outlet for opinions and as a resource for information about mental illness. ${ }^{20}$ Social media brings people from different parts of the world together for debate and discussion and the dissemination of information, and influence attitudes and health behaviour. ${ }^{20}$ Twitter is a micro-blogging platform allowing users to write tweets up to 140 characters in length. On Twitter, one can access a vast amount of data in a limited amount of time, compared with other social media outlets such as Facebook and YouTube, and people's tweets are easily accessible without a reader having an account Previous studies have investigated how schizophrenia is discussed on Twitter, finding a significant association with negative attitudes and opinions compared with depression and diabetes. ${ }^{21,22}$ However, as far as we are aware, no study has compared how schizophrenia and psychosis are discussed.

\section{Aims}

Therefore, the primary aim of this study was to investigate the use of schizophrenia and psychosis on Twitter and compare the relative proportions of negative use of the two terms. We tested the null hypothesis that there is no difference in the stigmatisation of psychosis compared with schizophrenia on Twitter.

\section{Method}

To identify tweets for the study, Twitter's advanced search tool was used on www.twitter.com to find tweets that contained the words 'schizophrenia' or 'schizophrenic', and 'psychosis' or 'psychotic' (we henceforth refer to these as schizophrenia/c and psychosis/tic) and were captured with NCapture (NCapture for Chrome, QSR International, Victoria Australia, available for download at https://www.qsrinternational.com/ nvivo/support-overview/downloads\#Download-NCaptureand-other-NVivo-add-ons). On NVivo (NVivo 12 for Mac, QSR International, Victoria Australia, available for download at https://www.qsrinternational.com/nvivo/support-overview/ downloads\#Download-NCapture-and-other-NVivo-add-ons), using an inductive coding method suggested by Reavley and Pilkington, ${ }^{21}$ tweets were coded based on the degree and nature of stigma toward schizophrenia/c and psychosis/tic as well as coding for user type and tweet content. Exclusion criteria were as follows:

(a) Lack of context: where the tweet was unable to be understood by the reader or the tweet was a spam tweet with no meaning behind it.

(b) Non-English: where all or the majority of the tweet was not in English.

(c) Repetition: where the tweet was exactly the same as another tweet in the data-set.

(d) Retweet: a reposted or forwarded tweet that was originally posted by another user.

If included, each tweet was coded into three or four categories, as follows:

(a) User type: individual, consumer, health professional, organisation and advocate.

(b) Tweet content: personal experience of mental illness, awareness promotion, research findings, resources for consumers, advertisement, news media and personal opinion/dyadic interaction.

(c) Attitude: stigmatising, personal experience of stigma, supportive, neutral and anti-stigma.

(d) (If category (c) indicated stigma) Stigma type: social distancing, dangerousness, snap out of it, personal weakness, inaccurate beliefs, mocking or trivialising and self-stigma. 


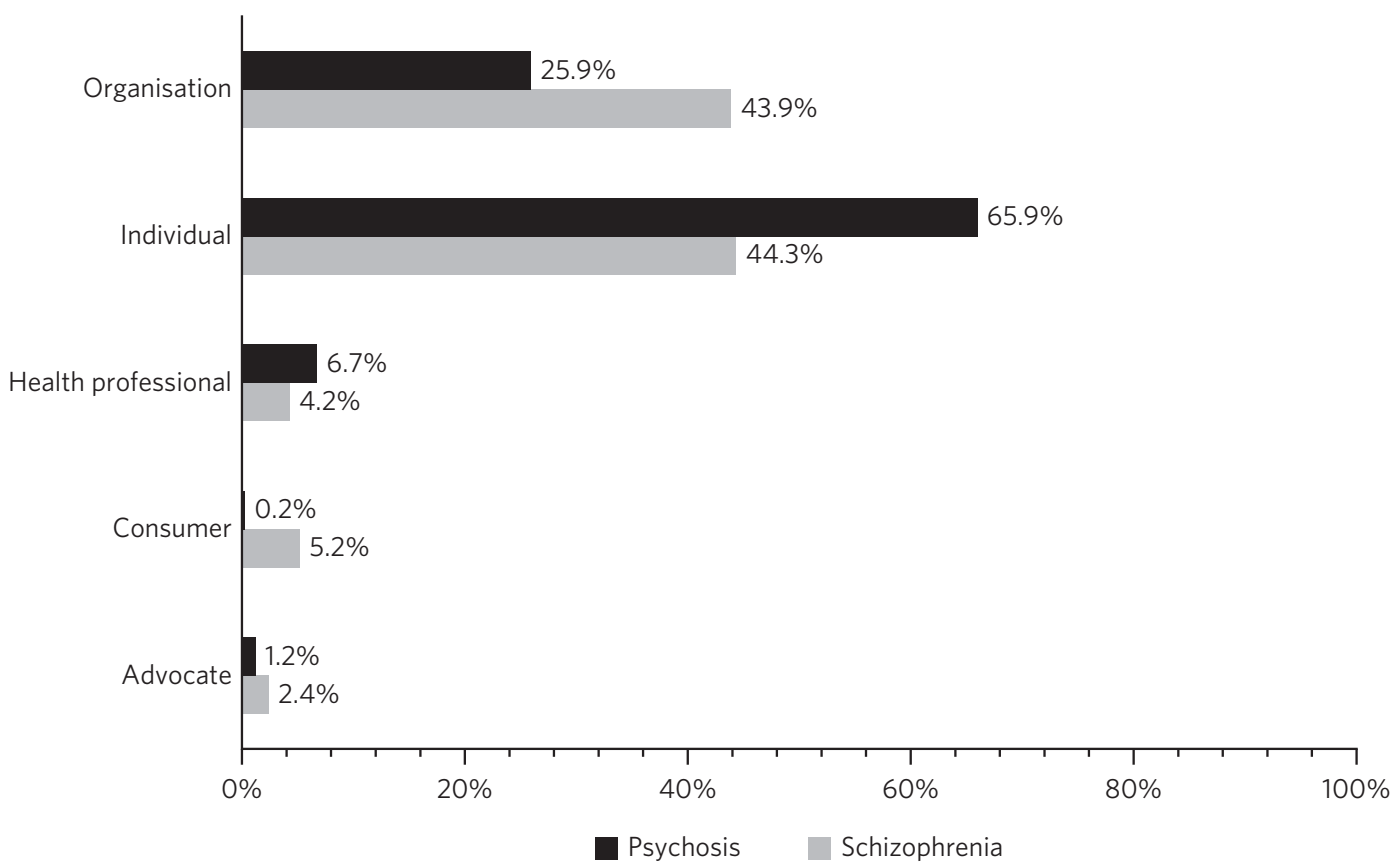

Fig. 1 Proportion of all tweets coming from each type of Twitter user.

G.L.P. and J.E.H. initially coded 100 tweets, using the categories and definitions from Reavley and Pilkington. ${ }^{21}$ Any tweets that were hard to categorise were discussed and resolved before J.E.H. and G.L.P. both coded $10 \%$ of the identified tweets to confirm the interrater agreement. The overall agreement was $87.6 \%$, illustrating that the coding method had high reliability. G.L.P. then coded all tweets from two 7-day periods: 16-22 April 2017 and 21-28 September 2017.
To analyse the data, $\chi^{2}$-tests were manually calculated to compare the proportions of the different types of tweets about schizophrenia/c versus psychosis/tic. These were compared with a $\chi^{2}$ table to determine the $P$-value, with a value of $P<0.05$ deemed significant.

We did not seek ethical approval for this study as it concerns the use of previously published material in the public domain.

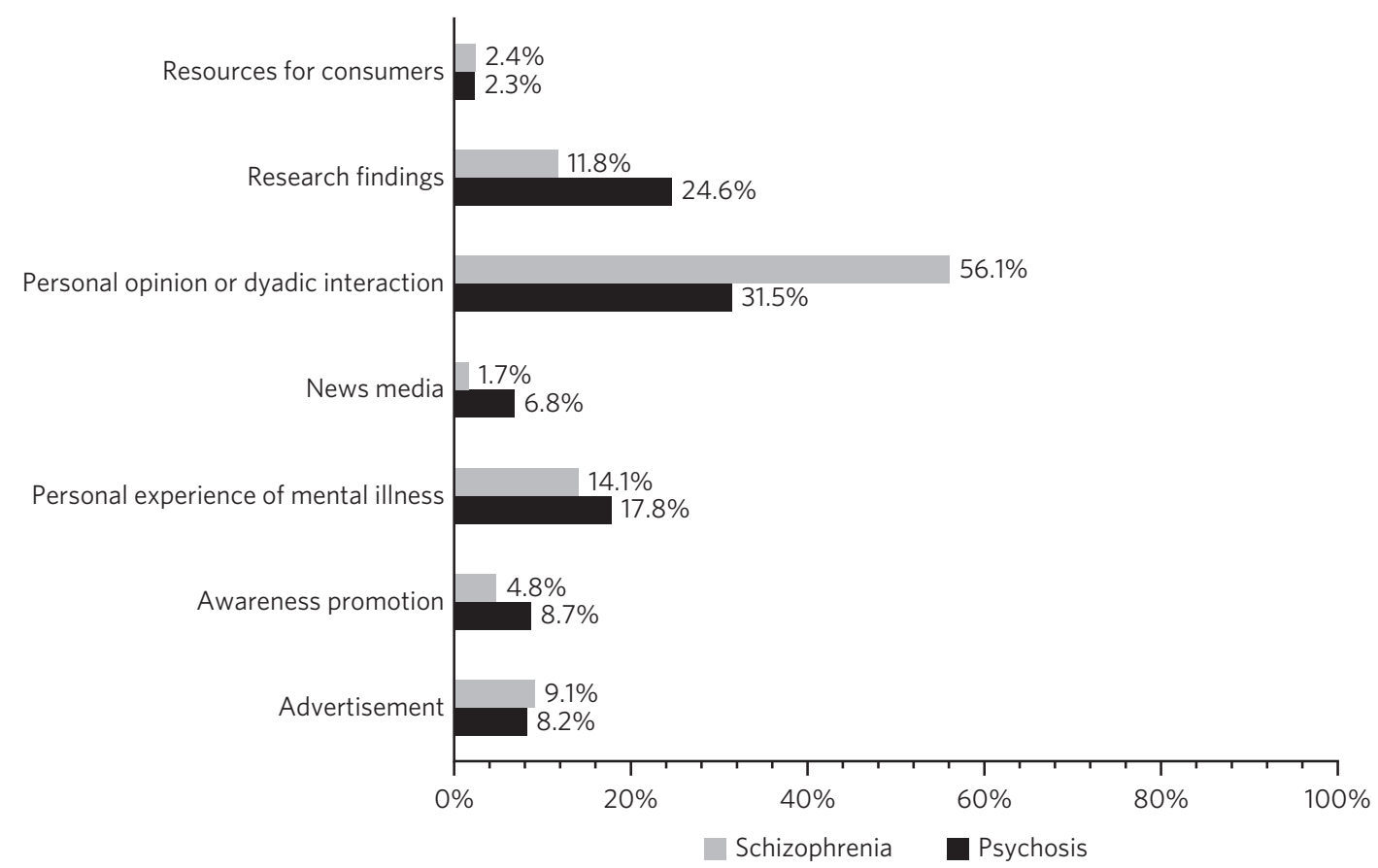

Fig. 2 The proportion of all tweets in each 'tweet content' category. 


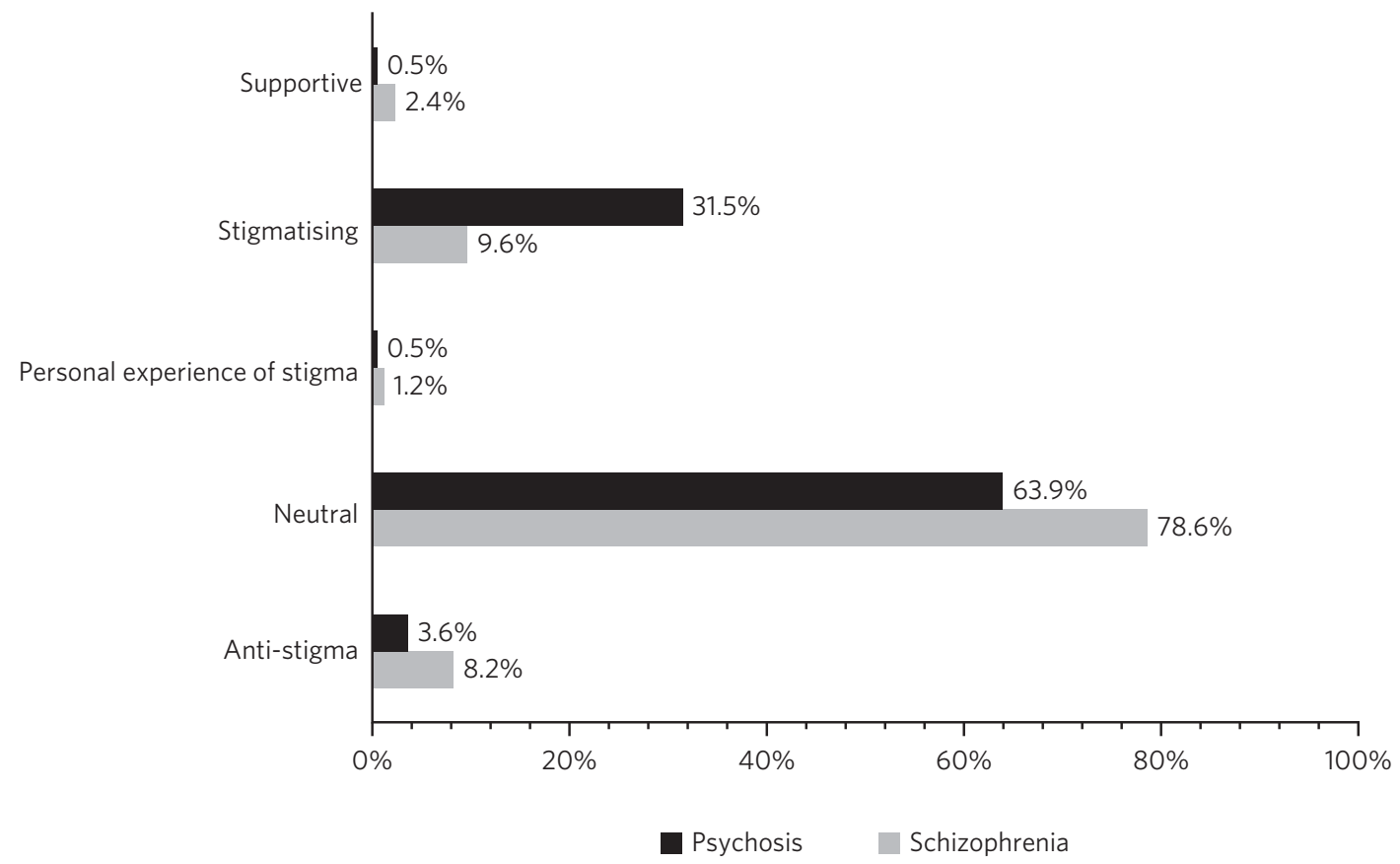

Fig. 3 The proportion of all tweets in each 'attitude' category.

\section{Results}

Examples of tweets in each category are shown in Appendix 1.

\section{Inclusion and exclusion}

The total number of schizophrenia/c tweets over the two 7-day periods was 1120 and the total number of psychosis/ tic tweets was 1080 over the two 7-day periods. We excluded $696(62.1 \%)$ schizophrenia tweets and 664 (61.5\%) psychosis tweets from the data-set based on the criteria above, leaving $424(37.9 \%)$ schizophrenia tweets and 416 (38.5\%) psychosis tweets in the analysis.

For schizophrenia/c, 490 (70.4\%) of the excluded tweets were retweets, 157 (22.6\%) were repetitions, 27 (3.9\%) were excluded because of lack of context and $22(3.2 \%)$ were not in English. For psychosis/tic, 560 (84.3\%) were retweets, 78 (11.7\%) were repetitions, $15(2.3 \%)$ were excluded because of lack of context and 11 (1.7\%) were not in English.

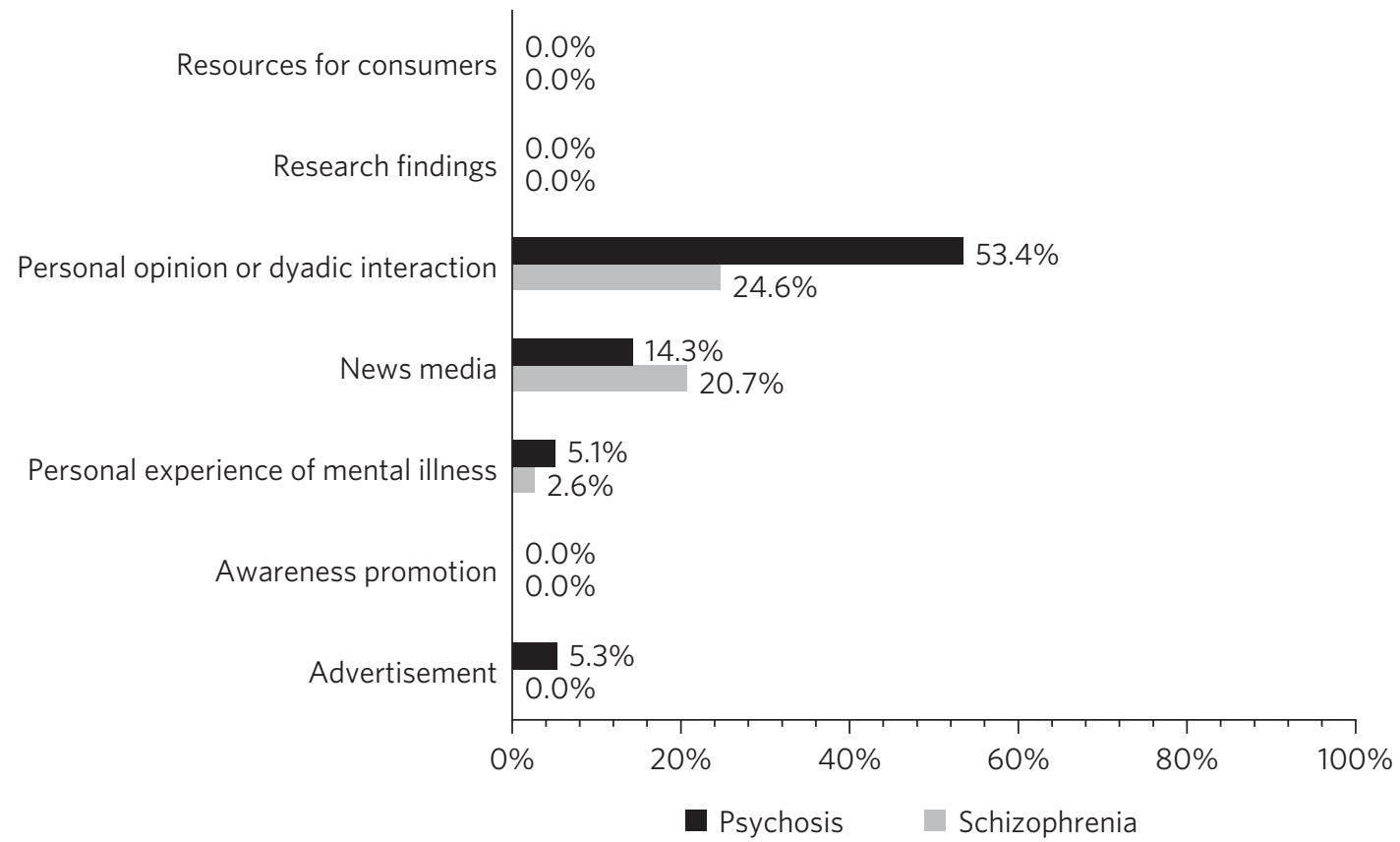

Fig. 4 The percentage of tweets that were stigmatising wtihin each 'tweet content' category. 


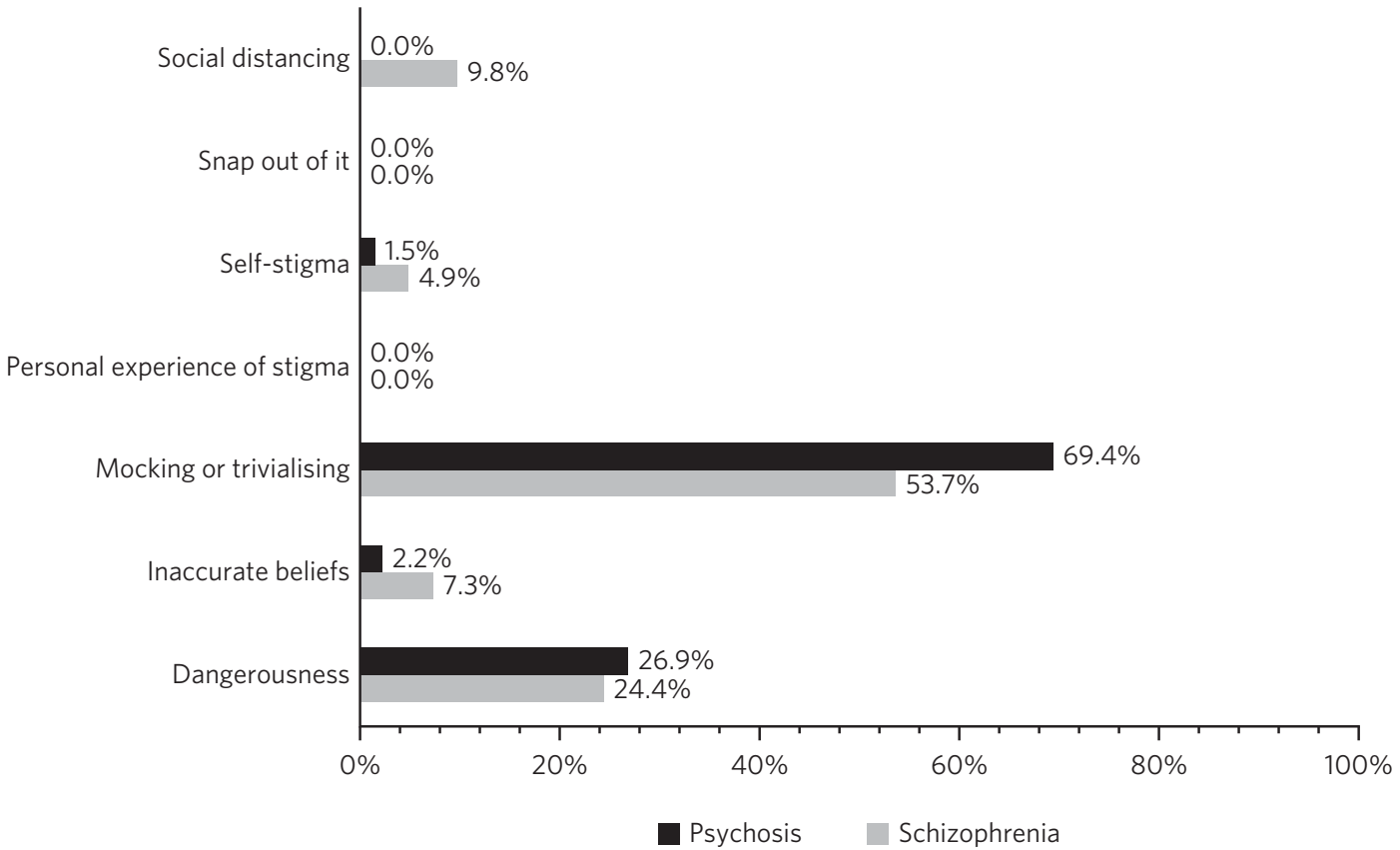

Fig. 5 Proportion of 'stigma type' in all stigmatising tweets.

\section{User type}

For schizophrenia/c, individuals ( $n=188,44.3 \%)$ and organisations $(n=186,43.9 \%)$ tweeted the most. This was followed by consumers $(n=22,5.2 \%)$, health professionals $(n=18$, $4.2 \%)$ and mental health advocates ( $n=10,2.4 \%)$.

For psychosis/tic, individuals tweeted the most $(n=275$, $65.9 \%)$, followed by organisations ( $n=108,25.9 \%)$, health professionals $(n=28,6.7 \%)$, mental health advocates $(n=5$, $1.2 \%)$ and consumers $(n=1,0.2 \%)$.

\section{Tweet content}

For schizophrenia/c, the tweets were most commonly personal opinions/dyadic interactions $(n=134,31.5 \%)$. This was followed by research findings ( $n=105,24.6 \%)$, experience of mental illness $(n=76,17.8 \%)$, awareness promotion $(n=37$, $8.7 \%)$, advertisement $(n=35,8.2 \%)$, news media $(n=29$, $6.8 \%$ ) and resources for consumers $(n=10,2.3 \%)$.

For psychosis/tic, the majority of tweets were also personal opinion/dyadic interaction $(n=234,56.1 \%)$. This was followed by experience of mental illness $(n=59,14.1 \%)$, research findings $(n=49,11.8 \%)$, advertisement $(n=38$, $9.1 \%)$, awareness promotion $(n=20,4.8 \%)$, resources for consumers $(n=10,2.4 \%)$ and news media $(n=7,1.7 \%)$.

\section{Attitude}

For both schizophrenia/c and psychosis/tic most of the tweets were neutral $(n=334,78.6 \%$ and $n=266,63.9 \%$, respectively). However, there was a significant difference in the number of stigmatising tweets: $41(9.6 \%)$ of the schizophrenia/c tweets were stigmatising, whereas 131 (31.5\%) of psychosis/tic tweets were. $\chi^{2}$-testing revealed a significant difference with a $\chi^{2}$ value of 237.03 (1 d.f., $P<0.0001$ ).

For schizophrenia/c, $35(8.2 \%)$ were anti-stigma, 10 (2.4\%) were supportive and $5(1.2 \%)$ were recounting a personal experience of stigma. For psychosis/tic, $15(3.6 \%)$ were anti-stigma, $2(0.5 \%)$ were supportive and $2(0.5 \%)$ recounted a personal experience of stigma.

When analysing the stigmatising tweets, it was found that for schizophrenia/c, 35 (85.4\%) came from individuals, $5(12.2 \%)$ came from organisations and 1 (2.4\%) came from a consumer. The vast majority of the stigmatising schizophrenia/c tweets were personal opinions/dyadic interactions $(n=33,80.5 \%)$. Six (14.6\%) were from news media and two $(4.9 \%)$ were about experience of mental illness.

In the stigmatised psychosis/tic tweets, 123 (94.6\%) came from individuals and $5(3.8 \%)$ came from organisations. Mental health advocates and consumers made up the other users, each tweeting one $(0.8 \%)$ of the stigmatising psychosis/tic tweets. Finally, 125 (95.4\%) of the stigmatised psychosis/tic tweets were personal opinion/dyadic interaction, $3(2.3 \%)$ were about experience of mental illness, 2 (1.5\%) were advertisements and 1 (0.8\%) was news media.

For schizophrenia/c, 33 (24.6\%) of personal opinions/ dyadic interactions were stigmatising and $6(20.7 \%)$ of the news media tweets were stigmatising. Two $(2.6 \%)$ of the schizophrenia/c tweets about experience of mental illness were stigmatising. For the other categories of tweet content, none of the tweets were stigmatising.

For psychosis/tic, 125 (53.4\%) of personal opinions/ dyadic interactions were stigmatising. One (14.3\%) of news media tweets was stigmatising, two (5.3\%) of the advertisement tweets were stigmatising and three $(5.1 \%)$ of tweets about experience of mental illness were stigmatising. The other categories did not contain any stigmatising tweets. Comparing the percentage of personal opinions/dyadic interactions that were stigmatising demonstrates a statistically significant difference, with a $\chi^{2}$ value of 44.65 ( 1 d.f., $P<$ 0.0001). 


\section{Stigma type}

Of the stigmatising schizophrenia/c tweets, 22 (53.7\%) were mocking or trivialising schizophrenia/c, 10 (24.4\%) were categorised as dangerousness, $4(9.8 \%)$ as social distancing, $3(7.3 \%)$ as inaccurate beliefs and $2(4.9 \%)$ as self-stigma.

For psychosis/tic, 93 (69.4\%) were categorised as mocking or trivialising, $36(26.9 \%)$ as dangerousness, $3(2.2 \%)$ as inaccurate beliefs and $2(1.5 \%)$ as self-stigma.

\section{Discussion}

The aim of this study was to assess any difference in views expressed about schizophrenia compared with psychosis on Twitter to assess the potential effect of a name change of schizophrenia. We found that the terms psychosis/tic were more commonly included in tweets expressing negative attitudes to these conditions than tweets referring to schizophrenia/c. Most of the stigmatising tweets were tweeted by individuals in the format of personal opinion/dyadic interactions. The most common forms of such stigmatisation were mocking, trivialisation or making associations with dangerousness. For both schizophrenia/c and psychosis/tic, however, the majority of tweets were non-stigmatising and provided potentially useful information, often about new research, normally broadcast by organisations.

\section{Comparisons with previous studies}

As far as we are aware, this is the first study to assess attitudes to schizophrenia compared with psychosis on Twitter or any other social medium. However, there are some previous studies that have compared attitudes to schizophrenia and other conditions on Twitter and on other social media. Reavley and Pilkington ${ }^{21}$ compared schizophrenia with depression on Twitter and found that there was a significantly greater stigmatisation toward schizophrenia: $5 \%$ of the schizophrenia tweets they identified $(n=451)$ were stigmatising. Joseph et $a l^{22}$ examined the use and misuse of schizophrenia on Twitter compared with diabetes and found a significantly greater proportion of schizophrenia tweets contained negative attitudes. Approximately one-third of their schizophrenia tweets had negative connotations $(n=685)$. Our figure of $9.35 \%(n=$ 424) falls in between what these two studies found. The difference in the percentage of schizophrenia tweets rated as stigmatising at different times could reflect coding differences but may be because of the effect of short-term changes in discussions about schizophrenia on Twitter.

There is some literature on the stigmatisation of schizophrenia and psychosis in entertainment media. A content analysis of Finnish and Greek videos on YouTube found that $83 \%$ of 52 videos portrayed schizophrenia in a negative way. ${ }^{23}$ Similarly, Nour et $a l^{24}$ found that most videos presenting schizophrenia on YouTube inaccurately portray the condition. Goodwin ${ }^{25}$ examined the stereotyping of characters experiencing psychosis in 33 psychosis-related horror films released before the study was conducted. He concluded that $78.8 \%$ portrayed a homicidal maniac and $72.7 \%$ portrayed a pathetic or sad character. This is in keeping with our finding that psychosis is heavily stigmatised.
News media are also a focal point for the stigmatisation of mental health conditions. Vilhauer ${ }^{26}$ analysed 181 USA newspaper articles mentioning the auditory verbal hallucinations that are diagnostic features of schizophrenia and other psychotic disorders. They found that about $50 \%$ of the articles associated auditory verbal hallucinations with criminal behaviour and violence. These findings are broadly in keeping with a more recent study that concluded that over half of all UK newspaper articles about mental health $(n=200)$ are negative and $18.5 \%$ indicate an association with violence. ${ }^{27}$

\section{Strengths and limitations}

The main strength of this study is its ability to assess peoples' uncensored views about schizophrenia and psychosis without the need of a survey, the results from which could be affected by social desirability bias. The nature of Twitter means that, once published, a tweet is accessible to anyone without further permission from the tweet's author. Relevant tweets were easy to access on www.twitter.com with the advanced search tool and the process of coding was relatively time-efficient and simple using NVivo.

There are, however, a few limitations of this study. First, capturing data for two arbitrarily chosen 7-day periods means that external events and news cycles may have affected the way people discuss schizophrenia and psychosis, perhaps reducing the generalisability of the data. Of note, there were news stories about USA's response to North Korean nuclear missile testing in the April 2017 observation period, ${ }^{28}$ and September 2017's period was soon after a bomb injured 30 people in London, England. ${ }^{29}$ A further study could look in detail about how news media and current affairs influence people's expression of mental illness on social media. A longer period of study could examine detail how current affairs influence people's discussion of mental illness on social media, and potentially highlight trends in how people discuss schizophrenia and psychosis.

Another limitation is that spelling mistakes, abbreviations and colloquial terms for the searched terms may be used in tweets. By searching for only 'schizophrenia, 'schizophrenic', 'psychosis' and 'psychotic', tweets containing mistakes, abbreviations and colloquial terms will not have been captured in the search. We decided not to include abbreviations and colloquial terms in the search because it may not be clear whether tweets would actually have been about schizophrenia and psychosis. An example would be the abbreviation 'psycho', which could refer to psychopath, rather than psychosis. However, if anything, it is more likely that spelling mistakes, abbreviations and colloquial terms may have higher rates of stigmatisation. In a similar vein, future studies could map the different definitions of schizophrenia/c and psychosis/tic used by lay individuals and professionals as this may influence the degree of stigmatising attitudes.

Both the 7-day window convenience sampling and the ability of users to privatise their Twitter accounts could have contributed to selection bias within the study. Content from private accounts would not be visible to our searches, and it would be an interesting but technically challenging study to assess whether private and public accounts have different levels of stigma. Selection bias is an often-encountered issue when conducting research on internet-based 
communications, and although an attempt to mitigate this was made by analysing all tweets from within the time frame, this may reduce the external validity of the conclusions. ${ }^{30}$

Finally, this study only looked on www.twitter.com and there are other social media platforms that could be assessed. Facebook data may be hard to access as the average person is likely to have their profile on a private setting, but it would be interesting to see if psychosis content on YouTube is as negative and inaccurate as it is for schizophrenia. Future work could also compare the stigmatisation of different psychoses on Twitter and other social media.

In conclusion, on Twitter, psychosis is more stigmatised than schizophrenia. This suggests that the term psychosis should not be used if schizophrenia is to be renamed with the aim of reducing stigma. Further, given that different psychotic disorders have particular treatments and varying prognoses, ${ }^{31,32}$ such a move to a more generic term may do more harm than good.

\section{About the authors}

Giorgianna L. Passerello is a medical student at Edinburgh Medical School, College of Medicine and Veterinary Medicine, University of Edinburgh, UK James E. Hazelwood (BMedSci) is a medical student at Edinburgh Medical School, College of Medicine and Veterinary Medicine, University of Edinburgh, UK. Stephen Lawrie (MD Hons) is Head of Psychiatry at the Royal Edinburgh Hospital, University of Edinburgh, UK

\begin{tabular}{|c|c|c|c|}
\hline \multirow[b]{2}{*}{ Category } & \multirow{2}{*}{$\begin{array}{l}\text { Definition of category (adapted } \\
\text { from Reavley and Pilkington }{ }^{21} \text { ) }\end{array}$} & \multicolumn{2}{|c|}{ Example tweet } \\
\hline & & Schizophrenia/schizophrenic & Psychosis/psychotic \\
\hline \multicolumn{4}{|l|}{ Tweet content } \\
\hline $\begin{array}{l}\text { Personal } \\
\text { experience of } \\
\text { mental illness }\end{array}$ & $\begin{array}{l}\text { The user expresses their personal } \\
\text { experience of having a mental } \\
\text { illness }\end{array}$ & $\begin{array}{l}\text { As a \#schizophrenic, my social brain is not } \\
\text { all what it could be. Twitter seems like an } \\
\text { avalanche of media frenzy } 24 / 7 \text { but maybe } \\
\text { I'm nub :/ }\end{array}$ & $\begin{array}{l}\text { Having a rough time lately with my } \\
\text { \#mentalhealth Feeling exhausted and } \\
\text { just not myself \#depression \#anxiety } \\
\text { \#psychosis }\end{array}$ \\
\hline $\begin{array}{l}\text { Awareness } \\
\text { promotion }\end{array}$ & $\begin{array}{l}\text { The user promotes awareness } \\
\text { about schizophrenia or psychosis } \\
\text { by providing information or } \\
\text { pointing readers in the direction of } \\
\text { where they can find information }\end{array}$ & $\begin{array}{l}\text { Schizophrenia truth and myths https://t.co/ } \\
\text { wGYFtMBNRa \#schizophrenia } \\
\text { \#mentalhealth }\end{array}$ & $\begin{array}{l}\text { Recognizing the symptoms is crucial in } \\
\text { order to help those suffering from } \\
\text { \#psychosis in \#mania https://t.co/ } \\
\text { W40srtD86J }\end{array}$ \\
\hline Research findings & $\begin{array}{l}\text { The user details outcomes in } \\
\text { research by summarizing or } \\
\text { linking to publications and articles }\end{array}$ & $\begin{array}{l}\text { \#Mental problems such as \#schizophrenia } \\
\text { and \#bipolar disorder could be linked to a } \\
\text { yeast infection in the \#gut https://t.co/ } \\
\text { v1u1CBQZod }\end{array}$ & $\begin{array}{l}\text { Young people with \#psychosis have a } \\
\text { 24× greater risk of death than their } \\
\text { peers: https://t.co/KnGBZjMZZA }\end{array}$ \\
\hline $\begin{array}{l}\text { Resources for } \\
\text { consumers }\end{array}$ & $\begin{array}{l}\text { The user points someone with a } \\
\text { mental illness in the direction of } \\
\text { helpful resources or provides } \\
\text { advice }\end{array}$ & $\begin{array}{l}\text { Did you check out our video library yet? It's } \\
\text { full of helpful resources about } \\
\text { \#schizophrenia \& \#psychosis https://t.co/ } \\
\text { CMuFhZb9QC }\end{array}$ & $\begin{array}{l}\text { Take a look at SMART - a new mental } \\
\text { health website for people who have } \\
\text { experienced psychosis! \#psychosis } \\
\text { \#recovery... https://t.co/ } \\
\text { 7Yk2Hh7Yas }\end{array}$ \\
\hline Advertisement & $\begin{array}{l}\text { The user advertises events or } \\
\text { products and services for sale }\end{array}$ & $\begin{array}{l}\text { Applications close soon: Neuroscience PhD } \\
\text { Projects in our lab (School of Medicine, Uni } \\
\text { of \#Wollongong \#Australia) http://bit.ly/ } \\
\text { 2y2D7Fs \#uow \#neuropharmacology } \\
\text { \#MedicinalCannabis \#cannabinoids } \\
\text { \#depression \#schizophrenia \#cognition } \\
\text { \#microbiota \#FindAPhD \#PhD } \\
\text { \#DoSomethingAmazing }\end{array}$ & $\begin{array}{l}\text { Don't miss HOAX Our Right to Hope } \\
\text { @HoaxOrth Award-winning trilogy of } \\
\text { art on \#psychosis Liverpool \& Salford } \\
\text { https://t.co/apUVQRNEYP }\end{array}$ \\
\hline News media & $\begin{array}{l}\text { The user tweets a summary of, or } \\
\text { hyperlink to, a news story }\end{array}$ & $\begin{array}{l}\text { Mental health trust is asked to take action } \\
\text { after death of Norwich man at hospital unit } \\
\text { \#schizophrenia \#bhive https://t.co/ } \\
\text { eZ51APnuCg }\end{array}$ & $\begin{array}{l}\text { Antiques Roadshow expert died after } \\
\text { psychotic episode, inquest hears } \\
\text {-\#postpartum \#psychosis https://t.co/ } \\
\text { IppuWm3N6O }\end{array}$ \\
\hline $\begin{array}{l}\text { Personal opinion/ } \\
\text { dyadic interaction }\end{array}$ & $\begin{array}{l}\text { The user in conversation with } \\
\text { someone or expressing their own } \\
\text { personal opinion or view }\end{array}$ & $\begin{array}{l}\text { Reading Bleed Through by Adriana Arrington } \\
\text { - this is one tough read \#Schizophrenia }\end{array}$ & $\begin{array}{l}\text { @donnabrazile and, now he's using the } \\
\text { moab to divert attention w NKorea. } \\
\text { \#psychosis ya think? }\end{array}$ \\
\hline \multicolumn{4}{|l|}{ Attitude } \\
\hline Stigmatising & $\begin{array}{l}\text { A tweet that expresses a negative } \\
\text { attitude toward schizophrenia or } \\
\text { psychosis }\end{array}$ & $\begin{array}{l}\text { As a woman, I'm laughing at this, because I } \\
\text { think these things are only things you've ever } \\
\text { heard inside your own head \#Schizophrenia } \\
\text { much? }\end{array}$ & $\begin{array}{l}\text { @realDonaldTrump Your level of } \\
\text { \#psychosis and \#sociopathic } \\
\text { tendencies is truly the only way you } \\
\text { sleep at night }\end{array}$ \\
\hline $\begin{array}{l}\text { Personal } \\
\text { experience of } \\
\text { stigma }\end{array}$ & $\begin{array}{l}\text { The user describes a personal } \\
\text { experience of being stigmatised } \\
\text { because of schizophrenia or } \\
\text { psychosis }\end{array}$ & $\begin{array}{l}\text { Being \#Schizophrenic, on a down phase, } \\
\text { relating traumas to therapist, they like to tell } \\
\text { me I'm a coldblooded emotionless } \\
\text { sociopath. ]No! \#Bipolar }\end{array}$ & $\begin{array}{l}\text { Moving account of how an experience } \\
\text { of \#psychosis and the \#stigma that } \\
\text { surrounds it, changed a life forever } \\
\text { https://t.co/yjkg3qAVbS }\end{array}$ \\
\hline
\end{tabular}




\begin{tabular}{|c|c|c|c|}
\hline \multicolumn{4}{|c|}{ Appendix 1 Continued } \\
\hline \multirow[b]{2}{*}{ Category } & \multirow{2}{*}{$\begin{array}{l}\text { Definition of category (adapted } \\
\text { from Reavley and Pilkington }{ }^{21} \text { ) }\end{array}$} & \multicolumn{2}{|c|}{ Example tweet } \\
\hline & & Schizophrenia/schizophrenic & Psychosis/psychotic \\
\hline Supportive & $\begin{array}{l}\text { The tweet is supportive to those } \\
\text { with schizophrenia or psychosis }\end{array}$ & $\begin{array}{l}\text { I love the insight into \#psychosis wish } \\
\text { everyone suffering could have access to } \\
\text { successful treatment } \\
\text { \#moneyformentalhealth }\end{array}$ & $\begin{array}{l}\text { Ty for your kindness. I also want to } \\
\text { send love and support to all those } \\
\text { suffering \#schizophrenia or } \\
\text { \#SchitzoAffectve as well as family } \\
\text { members }\end{array}$ \\
\hline Neutral & There is a neutral attitude & $\begin{array}{l}\text { Life goal achieved today! Writing for The } \\
\text { New York Times! https://t.co/pfz6757QRc } \\
\text { \#Schizophrenia \#mentalhealth } \\
\text { \#workingfromhome }\end{array}$ & $\begin{array}{l}\text { Let's do a Scottish sequel: Surviving } \\
\text { \#Psychosis https://t.co/IGufn98Wz9 }\end{array}$ \\
\hline Anti-stigma & $\begin{array}{l}\text { The tweet promotes a reduction in } \\
\text { stigma toward those with } \\
\text { schizophrenia or psychosis }\end{array}$ & $\begin{array}{l}\text { @pfrench123 Always great to see novel and } \\
\text { engaging ways to break down \#stigma in } \\
\text { \#psychosis. We hope the project does very } \\
\text { well }\end{array}$ & $\begin{array}{l}\text { MIND MATTERS: Mental illness } \\
\text { doesn't always lead to \#violence } \\
\text { https://buff.ly/2hsyzBn } \\
\text { \#schizophrenia \#bipolar \#treatment } \\
\text { \#getthefacts }\end{array}$ \\
\hline \multicolumn{4}{|l|}{ Stigma type } \\
\hline Social distancing & $\begin{array}{l}\text { The user expresses the wish to } \\
\text { have no contact with someone } \\
\text { with schizophrenia or psychosis }\end{array}$ & $\begin{array}{l}\text { \#IfYouSeeMelnRealLife you're not a } \\
\text { schizophrenic. If not go to your nearest } \\
\text { psychiatrist now! \#Schizophrenia } \\
\text { \#MentalHealthAwareness }\end{array}$ & $\mathrm{N} / \mathrm{A}$ \\
\hline Dangerousness & $\begin{array}{l}\text { The user implies that someone } \\
\text { with schizophrenia or psychosis is } \\
\text { dangerous and may cause harm }\end{array}$ & $\begin{array}{l}\text { Schizophrenic Canadian who beheaded bus } \\
\text { passenger walks free, won't be monitored } \\
\text { http://medicalnews.drifterup.com/News/ } \\
\text { Details/40640 ... \#Schizophrenia } \\
\text { @MedicalNewsLH }\end{array}$ & $\begin{array}{l}\text { Any excuse for \#war. \#American } \\
\text { politics has truly been taken over by } \\
\text { \#psychotic \#warmongers at the } \\
\text { detriment to \#humanity. } \\
\text { \#HandsOffSyria }\end{array}$ \\
\hline Snap out of it & $\begin{array}{l}\text { The user implies that the person } \\
\text { with schizophrenia or psychosis } \\
\text { can 'snap out of it' by choice }\end{array}$ & $N / A$ & $N / A$ \\
\hline $\begin{array}{l}\text { Personal } \\
\text { weakness }\end{array}$ & $\begin{array}{l}\text { The user implies that } \\
\text { schizophrenia or psychosis are } \\
\text { because of personal weakness }\end{array}$ & $N / A$ & $N / A$ \\
\hline Inaccurate beliefs & $\begin{array}{l}\text { The tweet indicates the user has a } \\
\text { lack of knowledge or inaccurate } \\
\text { beliefs about schizophrenia or } \\
\text { psychosis }\end{array}$ & $\begin{array}{l}\text { The US Government is a split personality... } \\
\text { \#Schizophrenia }\end{array}$ & $\begin{array}{l}\text { @ddanielsen you did all you could } \\
\text { @F1abraham can't be fixed, there's no } \\
\text { fixing a person who is that \#psychotic. } \\
\text { @MTV you made her fix it }\end{array}$ \\
\hline $\begin{array}{l}\text { Mocking or } \\
\text { trivialising }\end{array}$ & $\begin{array}{l}\text { (a) The user is rude, insulting or } \\
\text { trivialising toward someone with } \\
\text { schizophrenia or psychosis; (b) } \\
\text { The user uses schizophrenia or } \\
\text { psychosis as an insult }\end{array}$ & $\begin{array}{l}\text { Some people follow you, when you follow } \\
\text { back, they unfollow. \#Twitter } \\
\text { \#schizophrenia }\end{array}$ & $\begin{array}{l}\text { @Pamela_Moore13 What kind of drugs } \\
\text { is this POS on \#psychotic }\end{array}$ \\
\hline Self-stigma & $\begin{array}{l}\text { The tweet implies the user has } \\
\text { internalised a stigmatising attitude } \\
\text { toward schizophrenia or psychosis }\end{array}$ & $\begin{array}{l}\text { I'm going mad today though I've been } \\
\text { officially diagnosed as a crazy person. } \\
\text { Schizophrenia is a real downer } \\
\text { \#Schizophrenia \#hearingvoices }\end{array}$ & $\begin{array}{l}\text { I think I'm starting to realize that } \\
\text { everyone around me is a lot more in } \\
\text { touch with reality than I am. } \\
\text { \#psychosis \#mentalillness }\end{array}$ \\
\hline \multicolumn{4}{|l|}{ User type } \\
\hline Individual & $\begin{array}{l}\text { A user who does not specify } \\
\text { whether they suffer from a mental } \\
\text { illness }\end{array}$ & $\mathrm{N} / \mathrm{A}$ & $\mathrm{N} / \mathrm{A}$ \\
\hline Consumer & $\begin{array}{l}\text { A user who states on their profile, } \\
\text { or within the sample tweet, that } \\
\text { they suffer from a mental illness }\end{array}$ & $\mathrm{N} / \mathrm{A}$ & $\mathrm{N} / \mathrm{A}$ \\
\hline Organisations & $\begin{array}{l}\text { A user who states on their profile } \\
\text { that they are an organisation, or } \\
\text { group of people }\end{array}$ & $N / A$ & $N / A$ \\
\hline $\begin{array}{l}\text { Health } \\
\text { professionals }\end{array}$ & $\begin{array}{l}\text { A user who states on their profile, } \\
\text { or within the sample tweet, that } \\
\text { they are a healthcare professional }\end{array}$ & $\mathrm{N} / \mathrm{A}$ & $\mathrm{N} / \mathrm{A}$ \\
\hline $\begin{array}{l}\text { Mental health } \\
\text { advocate }\end{array}$ & $\begin{array}{l}\text { A user who states on their profile, } \\
\text { or within the sample tweet, that } \\
\text { they are a mental health advocate }\end{array}$ & $\mathrm{N} / \mathrm{A}$ & $N / A$ \\
\hline
\end{tabular}




\section{References}

1 American Psychiatric Association. Diagnostic and Statistical Manual of Mental Disorders (5th edn). American Psychiatric Association, 2013.

2 Tandon R, Gaebel W, Barch DM, Bustillo J, Gur RE, Heckers S, et al. Definition and description of schizophrenia in the DSM-5. Schizophr Res 2013; 150: 3-10.

3 van Os J, Kapur S. Schizophrenia. Lancet 2009; 374: 635-45.

4 Leucht S, Tardy M, Komossa K, Heres S, Kissling W, Salanti G, et al. Antipsychotic drugs versus placebo for relapse prevention in schizophrenia: a systematic review and meta-analysis. Lancet 2012; 379: 2063-71.

5 Sartorius N. Stigma and mental health. Lancet 2007; 370: 810-1.

6 Dockery L, Jeffery D, Schauman O, Williams P, Farrelly S, Bonnington O et al. Stigma- and non-stigma-related treatment barriers to mental healthcare reported by service users and caregivers. Psychiatry Res 2015; 228: 612-9.

7 O'Reilly CL, Bell JS, Kelly PJ, Chen TF. Exploring the relationship between mental health stigma, knowledge and provision of pharmacy services for consumers with schizophrenia. Res Soc Admin Pharm 2015; 11: e101-9.

8 Chan SKW, Kao SYS, Leung SL, Hui CLM, Lee EHM, Chang WC, et al. Relationship between neurocognitive function and clinical symptoms with self-stigma in patients with schizophrenia-spectrum disorders. $J$ Ment Health 2017; 1-6.

9 Lasalvia A, Penta E, Sartorius N, Henderson S. Should the label 'schizophrenia' be abandoned? Schizophr Res 2015; 162: 276-84.

10 Yamaguchi S, Mizuno M, Ojio Y, Sawada U, Matsunaga A, Ando S et al. Associations between renaming schizophrenia and stigma-related outcomes: a systematic review. Psychiatry Clin Neurosci 2017; 71: 347-62.

11 Koike S, Yamaguchi S, Ojio $Y$, Shimada $T$, Watanabe $K$, Ando $S$ Long-term effect of a name change for schizophrenia on reducing stigma. Soc Psychiatry Psychiatr Epidemiol 2015; 50: 1519-26.

12 Aoki A, Aoki Y, Goulden R, Kasai K, Thornicroft G, Henderson C. Change in newspaper coverage of schizophrenia in Japan over 20-year period. Schizophr Res 2016; 175: 193-7.

13 Sami MB, Shiers D, Latif S, Bhattacharyya S. Early psychosis for the nonspecialist doctor. BMJ 2017; 357: j4578.

14 Carpenter WT. Shifting paradigms and the term schizophrenia. Schizophr Bull 2016; 42: 863-4.

15 van Os J. 'Schizophrenia' does not exist. BMJ 2016; 352: i375.

16 Cooke A, Kinderman P. 'But what about real mental illnesses?' Alternatives to the disease model approach to 'Schizophrenia'. J Humanist Psychol 2018; 58: 47-71.

17 Cooke A, editor. Understanding Psychosis and Schizophrenia: Why People Sometimes Hear Voices, Believe Things That Others Find Strange, or Appear Out of Touch with Reality... and What Can Help (Revised edn). British Psychologial Society, 2017
18 Jääskeläinen E, Juola P, Hirvonen N, McGrath Jل Saha S, Isohanni M, et al. A systematic review and meta-analysis of recovery in schizophrenia. Schizophr Bull 2013; 39: 1296-306.

19 Lally J, Ajnakina O, Stubbs B, Cullinane M, Murphy KC, Gaughran F, et al. Remission and recovery from first-episode psychosis in adults: systematic review and meta-analysis of long-term outcome studies. Br J Psychiatry 2017; 211: 350-8.

20 Ashrafi-Rizi $\mathrm{H}$, Afshar $M$. The use of social media in health systems: opportunities and challenges. J Health Manage Inform 2015; 2: 65-6.

21 Reavley NJ, Pilkington PD. Use of Twitter to monitor attitudes toward depression and schizophrenia: an exploratory study. PeerJ 2014; 2: e647.

22 Joseph AJ, Tandon N, Yang LH, Duckworth K, Torous J, Seidman LJ, et al. \#Schizophrenia: use and misuse on Twitter. Schizophr Res 2015; 165: $111-5$.

23 Athanasopoulou C, Suni S, Hätönen H, Apostolakis I, Lionis C, Välimäki M. Attitudes towards schizophrenia on YouTube: a content analysis of Finnish and Greek videos. Inform Health Soc Care 2016; 41: 307-24.

24 Nour MM, Nour MH, Tsatalou O-M, Barrera A. Schizophrenia on YouTube. Psychiatr Serv 2017; 68: 70-4.

25 Goodwin J. The horror of stigma: psychosis and mental health care environments in twenty-first-century horror film (part II). Perspect Psychiatr Care 2014; 50: 224-34.

26 Vilhauer RP. Depictions of auditory verbal hallucinations in news media. Intern J Soc Psychiatry 2015; 61: 58-63.

27 Chen M, Lawrie S. Newspaper depictions of mental and physical health BJPsych Bull 2017; 41: 308-13.

28 Infoplease. April 2017 Current Events: World News. 2000-2017 Sandbox Networks, Inc. 2017 (https://www.infoplease.com/world/2017-currentevents/april-2017-current-events-world-news\#North Korean Ballistic Missile Test Fails on Launch).

29 Infoplease. September 2017 Current Events: World News: 30 Injured in London Bombing. 2000-2017 Sandbox Networks, 2017 (https://www. infoplease.com/world/2017-current-events/september-2017-currentevents-world-news\#30\%20Injured\%20in\%20London\%20Bombing).

30 Li D, Walejko G. SPLOGS AND ABANDONED BLOGS: the perils of sampling bloggers and their blogs. Inform Commun Soc 2008; 11: 279-96.

31 Lawrie SM, O'Donovan MC, Saks E, Burns T, Lieberman JA. Towards diagnostic markers for the psychoses. Lancet Psychiatry 2016; 3: 375-85.

32 Lawrie SM, O'Donovan MC, Saks E, Burns T, Lieberman JA. Improving classification of psychoses. Lancet Psychiatry 2016; 3: 367-74. 